\title{
PROBATION OF THE IMPROVED VACUUM-EVAPORATIVE APPARATUS FOR PRODUCING CONCENTRATED FRUIT-BERRY SEMI-PRODUCTS
}

\author{
Andrii Zahorulko \\ Department of Processes, Devices and Automation of Food Production ${ }^{1}$ \\ zagorulkoAN@hduht.edu.ua \\ Aleksey Zagorulko \\ Department of Processes, Devices and Automation of Food Production ${ }^{l}$ \\ zagorulko@hduht.edu.ua \\ Natalia Fedak \\ Department of Food Technology $y^{l}$ \\ fedaknv@ukr.net \\ Sergei Sabadash \\ Department of Engineering Technology of Food Production ${ }^{2}$ \\ s.v.sabadash@ukr.net \\ Dmytro Kazakov \\ Department of Engineering Technology of Food Production ${ }^{2}$ \\ sms.kazak.dd@ukr.net \\ Vitaliy Kolodnenko \\ Department of Tractors, Agricultural Machines and Transportation Technologies ${ }^{2}$ \\ kolodnenko_vn@ukr.net \\ ${ }^{1}$ Kharkiv State University of Food Technology and Trade \\ 333 Klochkivska str., Kharkiv, Ukraine, 61051 \\ ${ }^{2}$ Sumy National Agrarian University \\ 160 H. Kondratieva str., Sumy, Ukraine, 40021
}

\footnotetext{
Abstract

The aim of the research is to probate the improved vacuum-evaporative apparatus with a changed heating system and increased heat exchanging surface, designed for producing high-quality concentrated blended fruit-berry compositions. Such constructive solution allows to realize an even stabilizing temperature effect, achieved at the expanse of eliminating a steam heating tunic by using a mixer of the apparatus itself. This approach provides simplification of exploitation conditions of such apparatuses, increases the heat exchanging surface that results in decreasing the thermal processing duration at concentrating natural raw materials with a possibility to create original blended compositions of the high readiness degree on its base. For providing production of concentrated semi-products, it is offered to blend fruit-berry raw materials in integral compositions of the high readiness degree. Food semi-products, obtained by this way, differ by original organoleptic properties and increased structural-mechanical indices that give a possibility of their wide use in different branches of food industry and restaurant economy.

There is used a method of determining changes of the obtained structure of blended fruit-berry paste with different ratios of components, using the differential function for distribution of pores by radius that provides determination of an influence of each raw material on the obtained dispersion. It is established, that a composition, based on apple, cranberry and blackberry demonstrates a dispersion decrease at introducing cranberry within $25-35 \%$ and its growth at a concentration increase up to $45 \%(\bar{r}=1.8 \mathrm{~nm})$.

At the apparatus probation there is established the evenness provision of a heat flow from a flexible film resistant electric heater of the radiating type, used for heating. Thus, at the given temperature on the heater surface as $146^{\circ} \mathrm{C}$, a difference of temperature values in control points is within error.

The result of the gustatory examination proved an advantage of the obtained blended fruit-berry concentrated semi-product, characterized by the homogenous structure with a peasant color and original taste qualities.
} 
The offered innovative construction-technological idea allows to produce high-quality concentrated products at using the improved equipment with the even stabilizing temperature effect, decreased metal consumption and increased exploitation indices.

Keywords: vacuum-evaporative apparatus, fruit-berry raw material, blending, mixer with heating surface.

DOI: $10.21303 / 2504-5695.2019 .001064$

\section{Introduction}

The development of needs of consumption cooperation, directed on production of high-quality food products, conditions the permanent improvement of ways and apparatuses for natural raw materials processing. The use of just natural raw materials provides widening of the assortment of products with the complete or partial replacement of import substances in existent recipes that allows to get functional products of the high readiness degree [1].

According to the data of the International federation of organic agriculture movement (IFOAM), the total circulation of organic products in the world reached 60 bil dol [2]. They need transformation in food products of the high readiness degree, using innovation methods, introducing principally new or improved existent technologies and constructive realization of transforming processes. Most spread products are: pastes, dry concentrated and powder-like products, because characterized by the wide spectrum of use in different branches of food industry [3, 4]. Concentrated natural semi-products are characterized by original structural-mechanical and physiological properties alongside with the wide spectrum of use $[5,6]$. At processing the great attention must be paid to specific properties of raw materials that are in their fast loss and change under conditions of non-rational processing [7,8]. It conditions a necessity of using substantiated regime parameters for providing the high quality of obtained products. The special attention must be paid to heat-mass-exchanging operations, especially concentration, because just temperature has an essential influence on obtained properties. Especially computer modeling of the quantitative evaluation of heat conduction under boiling condition by measuring thermohydraulic parameters in real time is used for heat exchange imitation [9]. It essentially facilitates the study of determining the temperature field evenness in heating apparatuses.

The main task of food industry for today is to provide the consumption cooperation with high-quality products with a rational price. In most cases just a cost and quality of products condition their competitiveness and growth of consumers' demand [10,11]. It conditions the use of existent technological processes of concentrating natural raw materials under conditions of searching for new ways for improving the apparatus design for their realization [12]. Taking into account the aforesaid, the research aim may be formulated. It includes the study of the blending process of fruit-berry raw materials and obtained structure of a composition, determination of the distribution evenness of the heat flow from the flexible film resistant electric heater of the radiating type (FFREhRT) and organoleptic assessment of the obtained blended fruit-berry concentrated semi-product.

The aim of the work is to probate the improved vacuum-evaporative apparatus with a changed heating system and increased heat exchanging surface, designed for producing high-quality concentrated blended fruit-berry compositions with an even stabilizing temperature effect, achieved at the expanse of eliminating of a steam heating tunic by using electric heaters and heated mixer. This approach provides simplification of exploitation conditions of such apparatuses for concentrating natural raw materials and getting original blended compositions of the high readiness degree on its base.

\section{Materials and Methods}

The improved vacuum-evaporative apparatus with the increased heat exchanging surface for producing high-quality concentrated natural semi-products was probated at the scientific-learning center "New biotechnologies and equipment for producing food products with high healthy properties" at the Kharkiv state university of food and trade (Ukraine).

For realizing the set aim of eliminating the steam heating way, it is offered to use the modern electric heater - (FFREhRT) [13]. There is also used heating of the mixing device by placing 
the electric heater in its cavity that in general allowed to increase the heating exchange surface of the apparatus, to provide the stabilizing temperature effect and to shorten the thermal processing duration of raw materials.

Ripen fruit-berry raw materials, cultivated within the Kharkv region, were used for the studies: apple (Antonivka variety - big fruits of green-yellow color, of a bit conic form with white flesh), cranberry (Howes variety - berries with a middle diameter up to $16 \mathrm{~mm}$. The skin is lustrous red with flexible flesh) and blackberry (Maxwell Erly variety - berries of a middle size, black lustrous), Fig. 1. Blended puree-like masses were further obtained in the offered recipe ratios (Table 1).

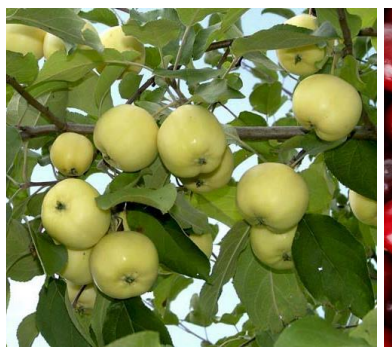

$a$

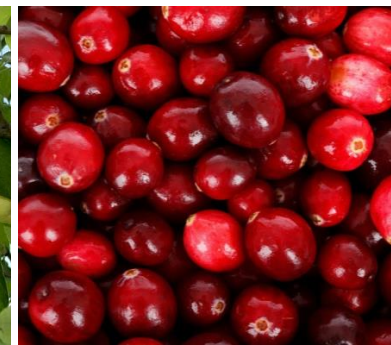

$b$

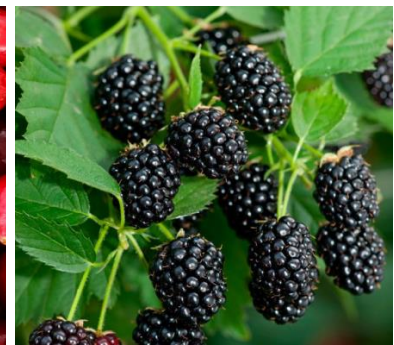

c

Fig 1. General outlook of the raw materials: $a$ - apple (Antonivka variety); $b$ - cranberry (Howes variety); $c$ - blackberry (Maxwell Erly variety)

Table 1

The component ratios at blending of fruit-berry raw materials

\begin{tabular}{lccc}
\hline \multicolumn{1}{c}{ Component composition } & a & b & c \\
\hline Apple & 60 & 70 & 50 \\
Cranberry & 35 & 25 & 45 \\
Blackberry & 5 & 5 & 5
\end{tabular}

Control (apple paste)

Blending of different raw materials allows to get original compositions with certain structural-mechanical and organoleptic properties and increased content of biologically active substances. The conventional way of producing blended fruit-berry pastes includes: inspection of raw materials, washing, blanching, rubbing, mixing, boiling, packing and sterilization. For revealing the optimal recipe ratio of blended compositions, there were produced samples with general mass $100 \mathrm{~g}$, taking into account the threefold iteration of the experiments. The analysis of the change of the obtained structure of blended compositions was realized by its comparison with the control - apple paste (Table 1). The change of the obtained structure was studied using the deferential function of pores distribution by radiuses (Fig. 3), in the blended composition of fruit-berry paste according to the component ratio (Table 1) and their comparison with the control (apple paste).

Apples and cranberries were blanched in the necessary weight $(1 \ldots 3 \mathrm{~kg})$ for conducting the studies for determining the obtained structure of blended composition according to the recipe with the offered ratio of components at blending the fruit-berry raw materials (Table 1). The process was realized in the model sample of a universal multifunctional apparatus (UMA) in $1 \ldots 2 \%$ solution of citric acid at temperature $60 \ldots 65^{\circ} \mathrm{C}$ during $2 \ldots 4 \mathrm{~min}$. [14]. There was used the experimental sample UMA-5 (maximal one-time load of the working volume at blanching $5 \mathrm{~kg}$ ), designed at the base of the scientific-learning center at the Kharkiv state university of food and trade. After rubbing the obtained puree was boiled on the experimental improved vacuum-evaporative apparatus with the increased heat exchanging surface at temperature $60 \ldots 65^{\circ} \mathrm{C}$, to content of dry substances $28 . . .30 \%$, which scheme is presented on Fig. 2 . 


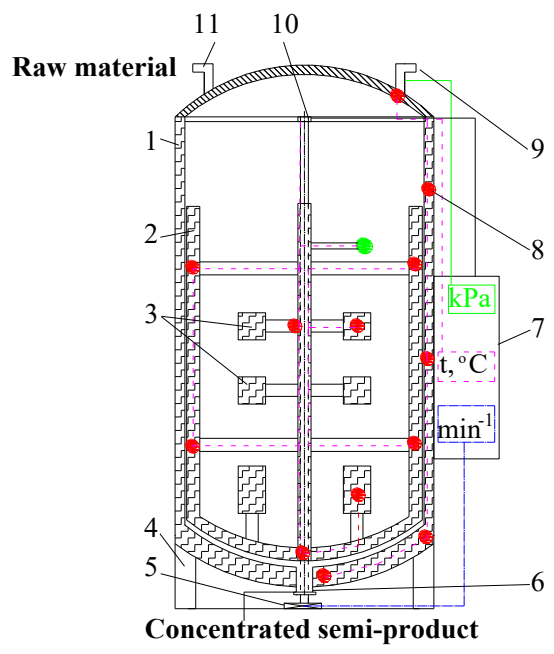

Fig 2. Scheme of the experimental vacuum-evaporative apparatus with the increased heat exchanging surface: places of thermocouples (8)

(the apparatus has standard means of an automatic closing-regulating armature, not presented on the scheme)

The working order of the experimental vacuum-evaporative apparatus with the increased heat exchanging surface is in fact that raw materials are loaded in the working chamber in the amount, preliminarily determined by the volumetric method, through branch pipe 11. After that there takes place the tightening of the chamber and vacuum creation $(13 \ldots 15 \mathrm{kPa})$ by the vacuum-pump through branch pipe 9. The working chamber is heated by FFREhRT 1, also placed in the internal volume of mixture 2 and auxiliary blades 3 . The apparatus is fixed on stands 4 , mixer rotation is realized through worm redactor 5, fixed in the lower part of the volume for facilitating exploitation conditions. Heating contacts of the mixer and thermocouples are connected by brush node 10 . The main regime parameters (mixer rotation frequency, temperature and vacuum in the apparatus) are regulated by managing block 7 , that allows to control the boiling process in real time. The fruit-berry concentrate is removed through branch pipe 6 .

\section{Experimental procedures}

The experimental-practical studies on probation of the improved vacuum-evaporative apparatus with the increased heat exchanging surface, designed for producing high-quality concentrated natural semi-products were realized according to preliminarily determined stages.

3. 1. Study of the impact of each component in the composition at blending the fruit-berry raw materials on the obtained structure

Changes of the obtained firmness of the blended fruit-berry compositions, preliminarily prepared by the ratio (Table 1), were determined by the differential function of pores distribution by radiuses (DFR), taking into account the average radius of the porous structure (r) [14]. At the studies at first there was found the values $a, b, W_{0}$, that are isotherms, obtained by the experimental way at: $\varphi=0.2, \varphi=0.5$ and $\varphi=0.8$ (Table $2, W$ ). With the further comparison with constants by: $\varphi=0.3, \varphi=0.6, \varphi=0.9$ (Table 2, $\Theta$ ). The obtained values $a$ and $b$ were averaged and further used for constructing DFR by formulas (1), (2).

The average radius of the porous structure of the obtained composition was determined by the equation:

$$
\bar{r}=\int_{r_{\min }}^{r_{\max }} r f(r) d r
$$

where $r_{\min }$ - minimal radius of microcapillaries; $r_{\max }$ - maximal radius of microcapillaries. 
At constructing the isotherms of sorption-desorption there was used the tensometric method of Van-Bammelen and equation:

$$
u=u_{0} \exp \left(-\frac{a_{293} \operatorname{In}(r)+b_{293}}{r}\right)
$$

where $u$-current humidity of the example, rel. un; $u_{0}$ - hygroscopic humidity at sorption, rel. un; $r$ - current radius of capillaries, $\mathrm{nm} ; \alpha_{293} ; b_{293}$ - constants, found, taking into account the outlook of the experimental isotherms of sorption-desorption by $T=293 \mathrm{~K}$.

Table 2 presents the obtained experimental values of balanced humidity of the compositions, blended by the recipe ratio (Table 1).

\section{Table 2}

Experimental values of initial humidity of the blended composition and calculative values of parameters of the isotherms and DFR

\begin{tabular}{ccccc}
\hline \multirow{2}{*}{ Constant isotherms } & \multicolumn{3}{c}{ Samples of compositions } & \multirow{2}{*}{ Control } \\
\cline { 2 - 4 } & $\mathbf{a}$ & $\mathbf{b}$ & 0.3 & 0.7 \\
\hline$W_{0}$ & 0.3 & 0.4 & 0.06 & 0.11 \\
$W_{0,2}$ & 0.05 & 0.10 & 0.11 & 0.12 \\
$W_{0,5}$ & 0.07 & 0.8 & 0.17 & 0.16 \\
$W_{0,8}$ & 0.11 & 0.9 & 0.2 & 1.32 \\
$a_{313}$ & 0.48 & 1.53 & 1.26 & 1.8 \\
$b_{313}$ & 1.4 & 0.71 & 4.5 & 1.0 \\
$\Theta_{0,3}$ & 1.72 & 3.2 & 2.9 & - \\
$\Theta_{0,6}$ & 2.4 & - & 1.15 & 0.10 \\
$\Theta_{0,9}$ & 1.31 & - & 8.6 & 1.1 \\
$\sum^{\Theta}$ & 5.25 & 3.0 &
\end{tabular}

The obtained analytic expressions of the blended compositions were described by the isotherms of sorption-desorption of DFR, presented on Fig. 3. The graphic presentation of the obtained results demonstrates the characteristic of the blended ratio of the composition by DFR with the correspondent $r_{\max }$, allowing to compare the influence of different ratios on the dispersion of the obtained blended semi-product, especially on the strength of the components' interaction in the recipe ratio.

3. 2. Study of the distribution evenness of the heat flow from FFREhRT without loading the apparatus with raw materials

For proving the distribution evenness of the heating flow from FFREhRT, thermocouples (point 8, Fig. 2), connected with the multichannel TRM, are placed on the working surface of the apparatus and heating mixer. Such placing of the thermocouples provided analyzing the thermal field evenness in real time, using the computer application TRM (Fig. 4).

The experimental studies on determining the distribution evenness of the heat flow from FFREhRT on the working surface of the apparatus and heating mixture were realized by placing thermocouples (point 8, Fig. 2), connected with the multichannel TRM [14].

\section{3. Study of the obtained organoleptic properties of the ready concentrated natural} semi-product

The expert commission of 5 members of the Kharkiv state university of food and trade (Kharkiv, Ukraine) at the probation of the vacuum-evaporative apparatus with the increased heat exchanging surface evaluated the concentrate of the blended composition by the 5-point scale by the organoleptic parameters, presented in Table 3. At the evaluation the experimental blended composition was compared with the control sample of apple paste. 


\section{Results}

At getting blended fruit-berry puree, based on: apples, cranberries and blackberries according to the recipe ratio (Table 2) the apple base with the highest content of pectin substances was used as a main component. Two other components served as admixtures with biologically active and coloring properties, inherent to them. The differential function of pores distribution by radiuses was used for analyzing the obtained structure firmness (Table 1) with the further mathematical calculation and graphic interpretation as isotherms of sorption-desorption, based on the tensometric method by Van-Bammelen and equations, included in it [13]. The obtained structure was compared with the control - apple paste that allowed to determine the interaction between the composition components.

The obtained curves of DFR of the blended samples are presented on Fig. 3. The obtained dispersion of the samples with a great number of microcapillaries with a less pores radius proves the big contact surface between components that positively influences their combination in the integral structure.

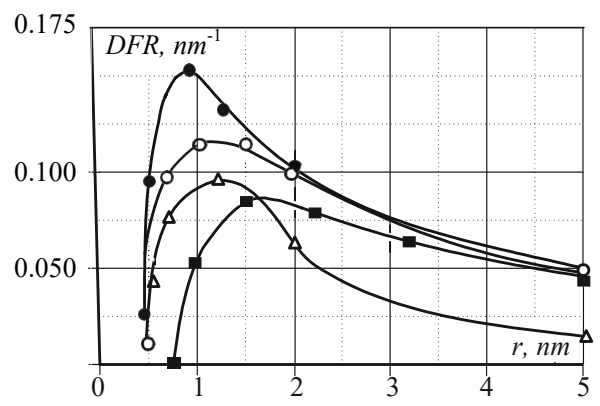

Fig. 3. Differential function of pores distribution by radiuses in the blended composition of fruitberry paste according to the component ratio (Table 1): $\bigcirc-60 \%$ of apple, $35 \%$ cranberry, $5 \%$ blackberry (a); $\Delta-70 \%$ of apple, $25 \%$ of cranberry, $5 \%$ blackberry (b); - (c) $50 \%$ of apple, $45 \%$ cranberry, $5 \%$ blackberry; - control (100\% of apple)

It has been established, that average radiuses of microcapillaries, taking into account $f(r)$ on Fig. 3, are: $a-\bar{r}=2.4 \mathrm{~nm}, b-\bar{r}=2.1 \mathrm{~nm}, c-\bar{r}=1.8 \mathrm{~nm}$ that proves the unessential difference in dispersion at the chosen ratio. But a tendency to dispersion decrease within cranberry introduction $25 \%(b)-35 \%(a)$ and dispersion growth at the further cranberry content increase up to $45 \%(c)$ is observed in the compositions. The comparison of the obtained dispersion with the control sample, taking into account the values of average radius of microcapillaries is characterized by deviations $\bar{r}$ between the samples $b$ and $a$, and by $13 \%$ at distinctness of the sorption method $15 \%$.

The study of the evenness distribution of the heat flow is proved by the data, obtained in real time from the thermocouples, placed according to Fig. 4.
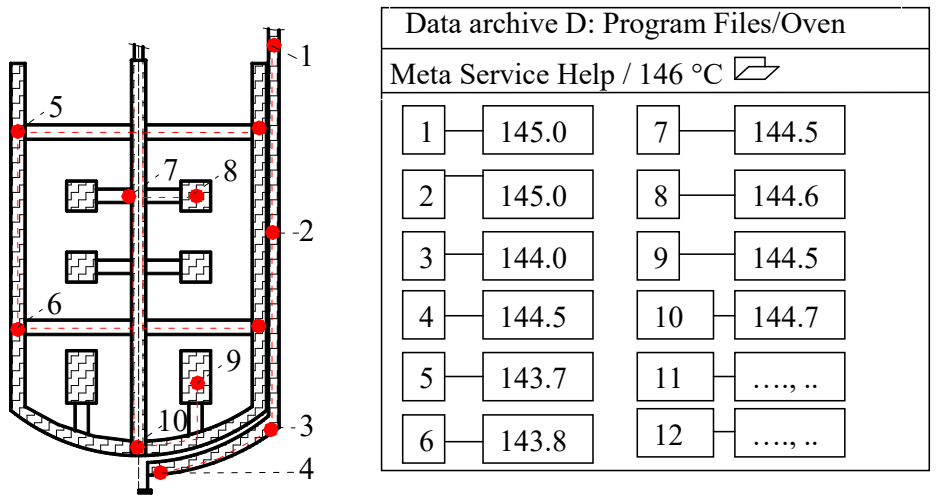

Fig. 4. Scheme of the thermocouples placement on the working surface of the apparatus and mixer under conditions of establishing the heater disconnection at $146{ }^{\circ} \mathrm{C}$ 
The thermocouples were connected with the 12-channel TRM and reflected by the computer program in real time by 10 thermocouples. The analysis of the obtained data proves the distribution evenness of the heat flow on the heating surfaces, and the difference in measuring was within error.

There was realized the organoleptic assessment of the experimentally obtained concentrated natural semi-products and control sample, which results are presented in Table 3.

Table 3

The results of the organoleptic assessment of the concentrated natural semi-product

\begin{tabular}{|c|c|c|c|c|c|}
\hline Sample of the concentrated natural semi-product & Outlook & Consistence & Taste & Natural color & Smell \\
\hline $\begin{array}{l}\text { Experimental sample concentrated semi-product } \\
\text { with } 30 \% \text { content of DS }\end{array}$ & 5 & 5 & 5 & 5 & 4 \\
\hline Control apple paste with $30 \%$ content of DS & 5 & 4 & 4 & 4 & 4 \\
\hline
\end{tabular}

Comparing the results of the visual and gustatory assessment, it is possible to prove the obtained high quality of the concentrated natural semi-product according to obtained gustatory marks at comparing. The offered innovative construction-technological ideas allow to produce high-quality concentrated products at using the improved equipment with the even stabilizing temperature effect.

\section{Discussion}

The solution of replacing the steam heating of the vacuum-evaporative apparatus by the electric one of FFREhRT provides the distribution evenness of the heat flow with the difference between the temperature values, obtained from the thermocouples, placed at control places of the surface no more $2.5^{\circ} \mathrm{C}$. The placing of the heater in the internal volume of the mixing device increased the total index of the heated surface by $12 \%$, in such a way shortening the heating term of raw materials by 4 min, comparing with a traditional constriction of the vacuum-evaporative apparatus.

The influence of each raw material of the paste on the obtained firmness of the blended semi-product by using the differential function of pores distribution by radiuses, taking into account the average radius of the components was assessed by the analytic way. The composition of apple, cranberry, blackberry demonstrates the dispersion decrease at introducing blackberry within $25-35 \%$ and its increase with the concentration growth up to $45 \%(\bar{r}=1.8 \mathrm{~nm})$. This approach allows to analyze the structure of pastes of different recipes and to produce their concentrated mixings with original functional-physiological properties, based on fruit-vegetable raw materials.

The results of the expert analytic evaluation prove the advantage of just the experimental sample of the concentrated semi-product, obtained at the apparatus probation, by organoleptic properties.

Advantages of the presented studies is the visual characteristic as to the change of the obtained firmness of the blended composition of natural origin, depending on ratio and average radius of the porous structure. It allows to determine the obtained blending structure and its firmness at the interaction with the surface by the graphic-analytic method. It provides widening the assortment of blended natural compositions with the certain structure and original taste properties.

The use of the vacuum-evaporative apparatus, improved by using FFREhRT, provides the increase of the total heating surface by $12 \%$, comparing with a traditional construction of vacuum-evaporating apparatuses. The high-quality stabilizing effect with the distribution evenness of the heat flow in the improved vacuum-evaporative apparatus provides the maximal preservation of natural properties of concentrated blended compositions at observing rational technological regimes.

The use of DFR for determining the obtained firmness of a mixing and its heat-mass-exchange processing in the improved equipment provides obtaining high-quality concentrated semi-products with original taste properties. The wide spectrum of use of blended concentrates in food industry provides getting functional products with the partial or complete replacement of certain ingredients.

\section{Conclusions}

The offered method of determining the change of the obtained structure of blended fruit-berry paste with different component ratios using the differential function of pores distribution by 
radius provides determination of the influence of each raw material on the dispersion of the obtained semi-products. The composition of apple, cranberry, blackberry demonstrates the dispersion decrease at introducing blackberry within 25-35\% and its increase with the concentration growth up to $45 \%(\bar{r}=1.8 \mathrm{~nm})$.

The probation of the vacuum-evaporative apparatus with the increased heat exchanging surface, heating of the working chamber and internal space of the mixer by the flexible film resistant electric heater of the radiating type provides the even distribution of the heat flow. Thus, at temperature on the heater surface $146^{\circ} \mathrm{C}$, the difference on the temperature values, obtained on the thermocouples, placed at control points, didn't exceed $2.5^{\circ} \mathrm{C}$. The gustatory examination proved the advantage of the obtained blended fruit-berry concentrated semi-product, characterized by the homogenous structure with a peasant color and original taste qualities.

\section{References}

[1] Funktsional'naya harakteristika pererabotannyh plodov i ovoshchey. Available at: https://znaytovar.ru/new708.html

[2] Vyrobnytstvo orhanichnoi silhospproduktsiyi ta syrovyny. Ahrobiznes sohodni. Available at: http://agro-business.com.ua/ agro/u-pravovomu-poli/item/1858-vyrobnytstvo-orhanichnoi-silhospproduktsii-ta-syrovyny.html

[3] Pylypenko, O. (2017). Development of Ukrainian food industry. Scientific Works of NUFT, 23 (3), 15-25.

[4] Asortyment plodovo-yahidnykh konserviv. Available at: http://foodtecnology.info/tehnologiya-pererobki-plodiv-ta-vochiv/ asortiment/asortiment-plodovo-yagidnih-konserviv

[5] Pavlyuk, R. Yu., Cherevko, A. I., Ukrainets, A. I. et. al. (2003). Novye fitodobavki i ih ispol'zovanie v produktah pitaniya. Kharkiv, 287.

[6] Marco, S.-C., Adrien, S., Isabelle, M., Manuel, V.-O., Dominique, P. (2019). Flash Vacuum-Expansion Process: Effect on the Sensory, Color and Texture Attributes of Avocado (Persea americana) Puree. Plant Foods for Human Nutrition, 74 (3), 370-375. doi: https://doi.org/10.1007/s11130-019-00749-3

[7] Pogarskaya, V. V, Cherevko, A. I., Pavlyuk, R. Yu. et. al. (2007). Novye tehnologii funktsional'nyh ozdrovitel'nyh produktov. Kharkiv, 262.

[8] Borchani, M., Masmoudi, M., Ben Amira, A., Abbès, F., Yaich, H., Besbes, S. et. al. (2019). Effect of enzymatic treatment and concentration method on chemical, rheological, microstructure and thermal properties of prickly pear syrup. LWT, 113, 108314. doi: https://doi.org/10.1016/j.lwt.2019.108314

[9] Hobold, G. M., da Silva, A. K. (2019). Visualization-based nucleate boiling heat flux quantification using machine learning. International Journal of Heat and Mass Transfer, 134, 511-520. doi: https://doi.org/10.1016/j.ijheatmasstransfer.2018.12.170

[10] Huang, L., Bai, L., Zhang, X., Gong, S. (2019). Re-understanding the antecedents of functional foods purchase: Mediating effect of purchase attitude and moderating effect of food neophobia. Food Quality and Preference, 73, 266-275. doi: https:// doi.org/10.1016/j.foodqual.2018.11.001

[11] Boesveldt, S., Bobowski, N., McCrickerd, K., Maître, I., Sulmont-Rossé, C., Forde, C. G. (2018). The changing role of the senses in food choice and food intake across the lifespan. Food Quality and Preference, 68, 80-89. doi: https://doi.org/10.1016/ j.foodqual.2018.02.004

[12] Costa, V., Johnson, A. (2019). Global Food and Nutrition Trends: Driving Positive Momentum for Grains. Cereal foods world, 64 (3). doi: https://doi.org/10.1094/cfw-64-3-0032

[13] Kiptelaya, L., Zahorulko, A., Zagorulko, A., Liashenko, B. (2017). Improvement of IR emitter to create non-reflector dryer for plant raw materials. Technology Audit and Production Reserves, 2 (3 (34)), 17-22. doi: https://doi.org/10.15587/23128372.2017.98068

[14] Zagorulko, A., Zahorulko, A., Kasabova, K., Chervonyi, V., Omelchenko, O., Sabadash, S. et. al. (2018). Universal multifunctional device for heat and mass exchange processes during organic raw material processing. Eastern-European Journal of Enterprise Technologies, 6 (1 (96)), 47-54. doi: https://doi.org/10.15587/1729-4061.2018.148443

[15] Cherevko, O. I., Mykhailov, V. M., Kiptela, L. V., Zakharenko, V. O., Zahorulko, O. Ye. (2015). Protsesy vyrobnytstva bahatokomponentnykh past iz orhanichnoi syrovyny. Kharkiv: KhDUKhT, 167.

[16] OWEN LLC. Available at: http://old.owen.ru/en+

Received date 03.10.2019

Accepted date 12.11.2019

Published date 30.11.2019
(C) The Author(s) 2019

This is an open access article under the CC BY license (http://creativecommons.org/licenses/by/4.0). 